Int. J. Electrochem. Sci., 14 (2019) $6179-6194$

International Journal of

ELECTROCHEMICAL

SCIENCE

WWW.electrochemsci.org

\title{
Anodic Oxidation of Phenoxyethanol in Nonaqueous Media
}

\author{
Magdalena Jakubczyk*, Slawomir Michalkiewicz. \\ Institute of Chemistry, Jan Kochanowski University, Swietokrzyska St. 15G, PL-25406 Kielce, Poland \\ "E-mail: magdalenajakubczyk2@ gmail.com
}

doi: $10.20964 / 2019.07 .69$

Received: 10 March 2019 / Accepted: 7 May 2019 / Published: 10 June 2019

The unknown electrochemical properties of phenoxyethanol (PE) - the most commonly used preservative in cosmetics were studied. The measurements were performed on platinum micro- and macroelectrodes by linear sweep (LSV), cyclic (CV) and differential pulse voltammetry (DPV) in mixed solvent acetic acid-acetonitrile $\left(20 \%\right.$, v/v) containing $\mathrm{NaClO}_{4}$ as a supporting electrolyte. The anodic oxidation process has proved to be quasireversible, diffusion-controlled and proceeding with exchange of one electron giving the unstable cation radical as a primary product $\left(E_{\mathrm{q}} C_{\mathrm{i}}\right.$ mechanism). Very good reproducibility of the DPV curves and the wide linearity range up to $1 \mathrm{mmol} \mathrm{L}^{-1}$ indicate that the proposed medium can be successfully applied to develop the first voltammetric method of this preservative determination in pharmaceutical and cosmetic products.

Keywords: Phenoxyethanol, Oxidation, Voltammetry, Acetic Acid, Acetonitrile

\section{FULL TEXT}

(C) 2019 The Authors. Published by ESG (www.electrochemsci.org). This article is an open access article distributed under the terms and conditions of the Creative Commons Attribution license (http://creativecommons.org/licenses/by/4.0/). 